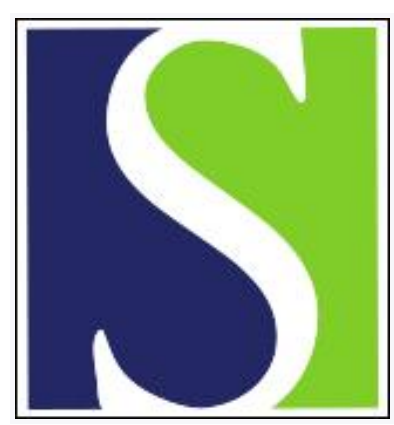

Scand J Work Environ Health 1997;23(5):392-393

https://doi.org/10.5271/sjweh.237

Issue date: Oct 1997

Developing national indicators for occupational health

by Takahashi K, Aw TC, Koh D, Wong TW, Kauppinen T, Westerholm P

This article in PubMed: www.ncbi.nlm.nih.gov/pubmed/9403471

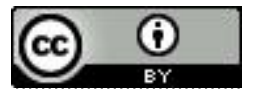




\title{
Developing national indicators for occupational health
}

\author{
by Ken Takahashi, MD, ${ }^{1}$ Tar Ching Aw, MD, ${ }^{2}$ David Koh, MD, ${ }^{3}$ Tze Wai Wong, MD, ${ }^{4}$ \\ Timo Kauppinen, $P h D,{ }^{5}$ Peter Westerholm, $M D^{6}$
}

\begin{abstract}
Takahashi K, Aw TC, Koh D, Wong TW, Kauppinen T, Westerholm P. Developing national indicators for occupational health. Scand J Work Environ Health 1997:23(5):392-3.
\end{abstract}

We believe that there is a case for developing, improving, and harmonizing national indicators for the occupational health status of populations. Several indicators are available in the field of public health. They include infant mortality rate, life expectation, number of physicians per 100000 population, and the like. For occupational health, the International Labour Office maintains statistics for fatal and nonfatal occupational injuries in several countries. However, there are, at present, no widely accepted, internationally approved, uniformly collected data sets that allow the production of occupational health status indicators that are comparable between countries. Two examples of such indicators are (i) the prevalence and incidence rate of occupational diseases and (ii) manpower and other resources for occupational health, for example, number of hygienists, occupational physicians, occupational health nurses, ergonomists, and so forth. These indicators would measure the progress of some of the priority objectives proposed by the World Health Organization (WHO) in its document Global Strategy on Occupational Health for All (1). The document proposes 2 global strategies: (i) the establishment of registration and data systems, the development of information services for experts, effective transmission of data, and the raising of public awareness through public information and (ii) the development of human resources for occupational health. There is a need to encourage coordination between international agencies involved in occupational health such as WHO and the International Labour Organisation (ILO) in their efforts to harmonize health-related statistics.
A problem with collecting and comparing statistical indices and data in occupational health lies in the basis and methods of collecting such data. Differences in national regulations, criteria, and practices contribute to this difficulty. For example, such problems have been observed in 2 European Union (EU) projects aimed at the production of comparative statistics on work accidents (2) and occupational diseases (3). Although national statistics may indicate the availability of social resources more than the state of occupational health, comparative indicators are valuable because they can stimulate discussion on the appropriateness of recording systems, data, and practices. They may also encourage international collaboration and the harmonization of such activities and result in more-complete reporting and in better-quality occupational health information.

One hurdle that needs to be overcome is agreement on the terminology and criteria for including data. For example, there should be some uniformity in the criteria for diagnosing occupational diseases. There should also be some commonality in systems for collecting such data. In regard to criteria for diagnosis, the EU has produced information notices on the diagnosis of occupational diseases (4). Systems for collecting data on the occurrence of occupational diseases often result in considerable underreporting. All of these practical issues need to be discussed and approved before progress towards developing comparable occupational health indicators is possible.

The WHO European Regional Office has been periodically monitoring the national situation on progress

1 Department of Environmental Epidemiology, University of Occupational and Environmental Health, Kitakyushu City, Japan.

2 Institute of Occupational Health, University of Birmingham, Birmingham, United Kingdom.

3 Department of Community, Occupational and Family Medicine, National University of Singapore, Singapore.

4 Department of Community and Family Medicine, The Chinese University of Hong Kong, Hong Kong.

5 Department of Epidemiology and Biostatistics, Finnish Institute of Occupational Health, Helsinki, Finland.

6 Department of Occupational Health, National Institute for Working Life, Solna, Sweden.

Reprint requests to: Dr Ken Takahashi, Department of Environmental Epidemiology, University of Occupational and Environmental Health, Orio, Yahatanishiku, Kitakyushu City 807, Japan. [E-mail: ktaka@med.uoeh-u.ac.jp] 
towards the WHO health-for-all (HFA) strategy (5) in member states. As a monitoring exercise, "HFA indicators" have been produced and member states have been requested to provide data for these indicators. The "HFA indicators" monitor different aspects of national health level, some of which are related to occupational health. Useful examples and their sources of information are listed in table 1 . The last 2 indicators to measure social resources could be translated to occupational health units and occupational health expenditure, respectively, and perhaps adjusted for the size of the working population. Although initiated in Europe, we believe that this solution could be a good basis for extending efforts to produce occupational health indicators on a global scale.

Some obstacles towards the development, collection, and utilization of national indicators in occupational health can readily be identified. ILO recognizes the limitations in even the existing indicators for occupational injuries in that "for various reasons, the national definitions of occupational injuries may differ from the recommended international standard definition, and they depend to a large extent on the source of the statistic" (6). This statement could be exaggerated for occupational diseases or there could be considerable underreporting, as has been shown in the United Kingdom with the statutory requirements for reporting occupational diseases (7). Despite these limitations, such indicators may be of value in the planning and evaluating of preventive activities. Internationally comparable indicators can be used to identify high-risk industries within a country to provide legislators and administrators with targets for preventive action. They can also be used to assess the comparative status of occupational health among countries and therefore provide international organizations with information with which to identify priority areas.

From the point of view of prevention, the development of hazard surveillance, and hence exposure indicators, would also be valuable. Although this need is widely recognized, there are practical difficulties in producing exposure indicators. There are differences between countries in the legal requirement to report the presence of hazards in workplaces or the occurrence of occupational ill-health. Large-scale industry-wide studies and field surveys are often expensive. The formation of teams that use agreed standardized definitions and assessment procedures may be a more rapid and valid method for producing statistical data on occupational hazards.

In conclusion, if national and international indicators for occupational health are to be developed beyond the reporting of occupational injuries, some important issues
Table 1. WHO health-for-all (HFA) indicators related to occupational health, adapted from reference 5. (ILO $=$ International Labour Office, $O E C D=$ Organization for Economic Corporation and Development)

\begin{tabular}{lc}
\hline Indicator & Source $^{a}$ \\
\hline Percentage of disabled of working age with regular & \\
occupation & E90 \\
Percentage of population with long-term work incapacity & E90 \\
$\begin{array}{l}\text { Number of persons injured in work-related accidents } \\
\text { Number of deaths due to work-related accidents }\end{array}$ & ILO \\
$\begin{array}{l}\text { Number of cases, certified occupation diseases, } \\
\text { persons 15-64 years of age }\end{array}$ & E84 \\
$\begin{array}{l}\text { Mortality, certified occupational diseases per 100 000, } \\
\text { persons 15-64 years of age }\end{array}$ & Not specified \\
$\begin{array}{l}\text { Annual lost workdays per person due to a certified } \\
\text { occupational disease }\end{array}$ & Not specified \\
Number of primary health care units & E90 \\
Public health expenditure as percentage of total & OCD \\
health expenditure & \\
\hline
\end{tabular}

a E90(84) = country reply; health-for-all evaluation exercise, 1990 (1984); $\mathrm{ILO}=$ Yearbook of Labour Statistics, ILO, Geneva; OCD = OECD health data base, Paris.

have to be resolved. These include determining the validity and benefit of indicators, facilitating the comparison of data from different countries, sorting out difficulties with disease registers, and considering options for developing countries to collect indicator information. These steps could stimulate research and discussion aimed at further improvements in global occupational health, based in part on the acquisition of comparable data and the use of experience from different countries.

\section{References}

1. World Health Organization (WHO). Global strategy on occlpational health for all - the way to health at work. Geneva: WHO, 1995

2. Eurostat. Accidents at work in the European Union in 1993: initial results. Eurostat, 1997. Statistics in focus 1997/2.

3. Laursen P, Netterstrom B, Gyntelberg F, Jorgensen K. Reporting occupational diseases in the European Community, phase 1: final report. Copenhagen: 1992.

4. European Commission. Information notices on diagnosis of occupational diseases. Luxenburg: Office for Official Publications of the European Communities, 1994. Health and safety report, EUR 14768.

5. World Health Organization (WHO) Regional Office for Europe. Printout of HFA database and some other data available in the WHO Regional Office for Europe. Copenhagen: WHO Regional Office for Europe, 1994.

6. International Labour Office (ILO). Occupational injuries. In: International Labour Office, editor. Year book of labour statistics, 1993, 52nd issue. Geneva: ILO Publications, 1993: 1049.

7. Health \& Safety Executive (HSE). A guide to the reporting of injuries diseases \& dangerous occurrences regulations 1995. Sheffield: HSE Books, 1996. 